Colon/Rectum

\title{
Challenges to accomplish stringent fluid management standards 7 years after enhanced recovery after surgery implementation-The surgeon's perspective
}

\author{
Fabian Grass, MD ${ }^{\mathrm{a}, \mathrm{b}}$, Martin Hübner, MD ${ }^{\mathrm{b}}$, Kellie L. Mathis, $\mathrm{MD}^{\mathrm{a}}$, Dieter Hahnloser, MD ${ }^{\mathrm{b}}$, \\ Eric J. Dozois, MD ${ }^{\mathrm{a}}$, Scott R. Kelley, MD ${ }^{\mathrm{a}}$, Nicolas Demartines, MD ${ }^{\mathrm{b}}$, \\ David W. Larson, MD, MBA ${ }^{\mathrm{a} \text {,* }}$ \\ a Division of Colon and Rectal Surgery, Mayo Clinic, 200 First Street SW, Rochester, MN \\ ${ }^{\mathrm{b}}$ Department of Visceral Surgery, Lausanne University Hospital (CHUV), University of Lausanne (UNIL), Lausanne, Switzerland
}

\section{A R T I C L E I N F O}

\section{Article history:}

Accepted 24 January 2020

Available online 28 February 2020

\begin{abstract}
A B S T R A C T
Background: This study aimed to analyze fluid management standards in 2 high-volume, enhanced recovery after surgery institutions 7 years after implementation.

Methods: Retrospective analysis of consecutive patients undergoing elective, segmental colonic and extensive colorectal resections for benign and malignant pathology (2011-2017). Administration and composition of intravenous fluids, postoperative weight gain, and factors impeding compliance to preidentified fluid thresholds (3L fluid administration, $2.5 \mathrm{~kg}$ weight gain) were assessed. Multivariable logistic regression was performed to identify risk factors for postoperative adverse events.

Results: A total of 5,155 patients were included. Among them, 2,320 patients (45.1\%) received $>3 \mathrm{~L}$ intravenous fluids at postoperative day 0 . Fluid totals remained unchanged over the 7-year observation period. Fluid overload was independently associated with postoperative weight gain $\geq 2.5 \mathrm{~kg}$ at postoperative day 2 (odds ratio 1.34, $P<.001$ ). Patients with high American Society of Anesthesiologists score $(\geq 3)$ undergoing open and longer $(\geq 180$ minutes) procedures were more likely to exceed both thresholds according to multivariable analysis (all $P<.001$ ). Other than open surgery, American Society of Anesthesiologists score $\geq 3$, contamination class $\geq 3$, and malignancy, both thresholds ( $\geq 3$ L: odds ratio 1.76 , $95 \%$ confidence interval $1.44-2.15, \geq 2.5 \mathrm{~kg}$ : odds ratio 1.62 , 95\% confidence interval $1.33-1.97$ ) were independent risk factors for postoperative adverse outcomes (occurring in $28.1 \%$ of patients).

Conclusion: Compliance with fluid thresholds appears to be challenging in patients with comorbidities undergoing open and long procedures. Efforts are encouraged because both thresholds are linked to adverse outcomes and appear to be potentially modifiable in selected patients.
\end{abstract}

(C) 2020 Elsevier Inc. All rights reserved.

\section{Introduction}

Optimal fluid management during major surgical procedures is a matter of ongoing debate. ${ }^{1-3}$ Although excessive fluid administration impedes functional recovery, concerns about overly restrictive management were raised recently by a randomized controlled trial. ${ }^{4,5}$ Enhanced recovery after surgery (ERAS) guidelines advocate balanced intravenous fluids without routine use of invasive monitoring for elective colorectal pro-

\footnotetext{
* Reprint requests: David W. Larson, MD, MBA, Division of Colon and Rectal Surgery, Professor of Surgery, Mayo Clinic, 200 First Street SW, Rochester, MN 55905.

E-mail address: larson.david2@mayo.edu (D.W. Larson).
}

cedures. ${ }^{6,7}$ Although there is a general consensus that fluid overload needs to be avoided, clear definitions of a stringent fluid regimen are lacking. ${ }^{8}$ In 2015, an international multicenter study of the ERAS compliance group defined empirically compliance as $<3,000 \mathrm{~mL}$ for colonic and $<3,500 \mathrm{~mL}$ for rectal resections on the day of surgery. ${ }^{9}$ Interestingly, over $60 \%$ of centers exceeded these thresholds, and restrictive intravenous fluid management was identified as the most protective factor against postoperative complications. Recent institutional publications calculated a threshold of $3 \mathrm{~L}$ through receiver operating characteristic analysis. ${ }^{10,11}$ However, whether fluid management has evolved because implementation of the ERAS guidelines has not been assessed yet. Furthermore, better understanding of demographic and surgical factors leading to both fluid overload 
and excessive postoperative weight gain is important to better define indications for counter-regulatory measures.

This study aimed to assess compliance and learning curve related to a stringent fluid management strategy within ERAS, to identify risk factors for non-compliance, and to assess clinical consequences of fluid overload and excessive weight gain through a merged data registry of 2 ERAS pioneer centers.

\section{Methods}

This is a retrospective cohort study with data deriving from 2 high volume referral centers, the Division of Colon and Rectal Surgery at Mayo Clinic, Rochester, Minnesota, and the Department of Visceral Surgery, Lausanne University Hospital CHUV, Lausanne, Switzerland. Both departments can attest to similar longstanding experience with ERAS, which became standard of care in both institutions in 2011. ${ }^{12,13}$ Data was collected prospectively by dedicated staff and stored in institutional data registries. Ethical approval of the respective institutional review boards was obtained (Lausanne CER-VD, \# 2017-01991, Rochester \# 16-004192).

Included were consecutive adult patients undergoing major $(>2$ hours, general anesthesia) elective colorectal resections for benign and malignant indications between January 2011 and December 2017. Demographic information and surgical details were assessed according to previously described methodology. ${ }^{14-17}$ Malnutrition was defined as preoperative (within 30 days of surgery) serum albumin $<3.5 \mathrm{~g} / \mathrm{L}$ and body mass index $\leq 18 \mathrm{~kg} / \mathrm{m}^{2}{ }^{2}$ Reconstructive surgeries without resection (ie, prolapse surgery, ostomy reversal) were not included. Left, transverse, and right colectomies were regrouped as segmental resections, whereas total colectomies and rectal resections were denominated extended resections.

\section{Perioperative fluid management and assessment}

As a key component of ERAS, a stringent fluid administration policy in line with ERAS Society guidelines, ${ }^{12,13}$ recommendations of the American Society of Enhanced Recovery, ${ }^{6}$ and associated perioperative fluid management guidelines ${ }^{18}$ was followed by both institutions, aiming for near 0 fluid balance and euvolemia as a general principle. A goal-directed fluid management strategy with invasive monitoring was reserved for high-risk procedures according to anesthesiologists' appraisals but not routinely considered in the elective setting of this study. ${ }^{18}$ Isotonic crystalloids were primarily considered for volume resuscitation. Oliguria did not trigger fluid therapy if occurring in isolation. ${ }^{19}$ Patients were given unrestricted access to oral fluids upon complete reversal of anesthesia.

Administered intravenous (IV) fluids including crystalloids, colloids, packed red blood cells, and albumin were totaled intraoperatively (start to end of anesthesia), in the post anesthesia care unit, and until midnight to calculate total amount of IV fluids on the day of surgery. Based on previous studies, a cutoff of $3 \mathrm{~L}$ was set. ${ }^{10,20}$ Weight was assessed preoperatively (within 1 month of surgery, referral weight) and on postoperative days (PODs) 1,2 , and 3. A recently validated threshold of $2.5 \mathrm{~kg}$ at POD 2 was defined. ${ }^{10,21}$ Further recorded were amounts of orally ingested liquids at POD 0 through POD 2. In a second step, both IV fluids and weight were correlated to different patient- and surgery-related characteristics including American Society of Anesthesiologists (ASA) score, type and duration of surgery, length of stay, and calendar year.

\section{Outcomes}

The primary endpoint was any complication occurring within 30 days of surgery classified according to the Clavien grading scale. ${ }^{22}$

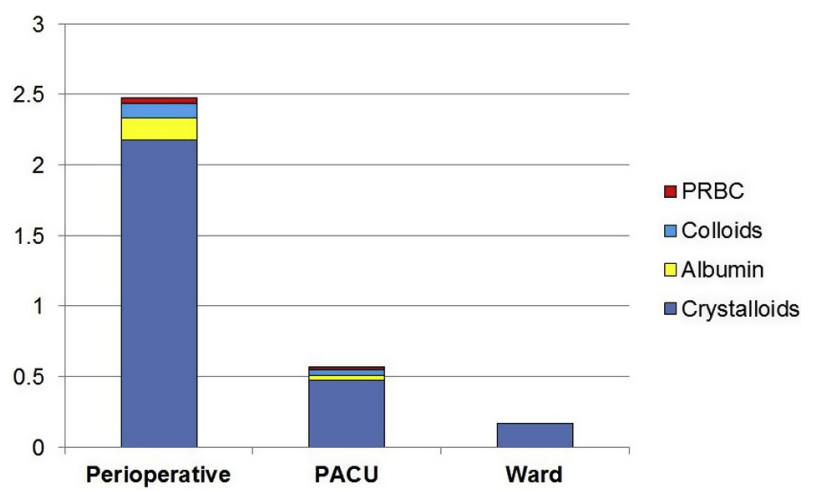

Fig 1. Composition of total intravenous fluids administered at the day of surgery. Composition of IV fluids administered at the day of surgery perioperatively (inductionreversal of anesthesia), at the postanesthesia care unit, and the surgical ward $(n=5,157)$. Displayed are mean values. PRBC, packed red blood cells.

Demographic and surgical characteristics and fluid management-related details were compared between patients with and without complications.

Demographic conditions or surgical specifics impeding compliance to predefined fluid thresholds ( $\geq 3$ L at POD 0) and weight gain ( $\geq 2.5 \mathrm{~kg}$ at POD 2 ) were identified through univariate and multivariable analysis.

\section{Statistical analysis}

Descriptive statistics for categorical variables were reported as frequency (\%), and continuous variables were reported as mean (standard deviation) or median (interquartile range) as appropriate. The $\chi^{2}$ test was used to compare categorical variables and the Student's $t$ test for continuous variables. All statistical tests were 2-sided and a level of .05 was used to indicate statistical significance. Multinominal logistic regression was performed to compute adjusted estimations of odds ratio (OR) to any complication, fluid overload ( $\geq 3 \mathrm{~L}$ ), and excessive weight gain $(\geq 2.5 \mathrm{~kg}$ ). Because values were available in only 1,686 patients $(32.7 \%$, no routine assessment), albumin was not retained for the multivariable model. Statistical correlations were computed through Pearson's rank correlation.

Data analysis was performed with the Statistical Software for the Social Sciences SPSS Advanced Statistics 22 (IBM Software Group, Chicago, IL) and GraphPad Prism Software 8 (San Diego, CA).

\section{Results}

Mean IV fluids at POD 0 in 5,155 patients totaled 3,180 $\pm 1,800 \mathrm{~mL}$, with 2,320 patients $(45.1 \%)$ receiving $>3 \mathrm{~L}$. IV fluids were mainly crystalloids ( $83.3 \%)$, followed by albumin ( $8.2 \%$ ), colloids $(6.3 \%)$, and packed red blood cells (2.2\%), as illustrated in Fig 1. Postoperative weight gain in patients receiving $>3 \mathrm{~L}$ was $3.1 \pm 6.1 \mathrm{~kg}$ vs $2.2 \pm 5.7 \mathrm{~kg}$ in patients receiving $<3 \mathrm{~L}$ at $\mathrm{POD} 1(P=.001), 3.3 \pm 5.9 \mathrm{~kg}$ vs $2.4 \pm 6.2$ $\mathrm{kg}$ at POD $2(P<.001)$, and $1.9 \pm 5.7 \mathrm{~kg}$ vs $1.4 \pm 4.8 \mathrm{~kg}$ at POD 3 $(P=.067)$. Fluid management remained unchanged since the first year of ERAS implementation (2011) until 2017 (Fig 2).

Table I displays demographic and surgical details of the cohort, comparing patients with complications ( $n=1,450,28.1 \%)$ to the remaining cohort. More detailed analysis of fluids and weight with regard to ASA score and type of surgery is displayed in Fig 3, revealing significant differences across ASA scores and type of procedure, with rectal resections being more prone to important fluid administration and weight gain, respectively (all $P<.001$ ). 


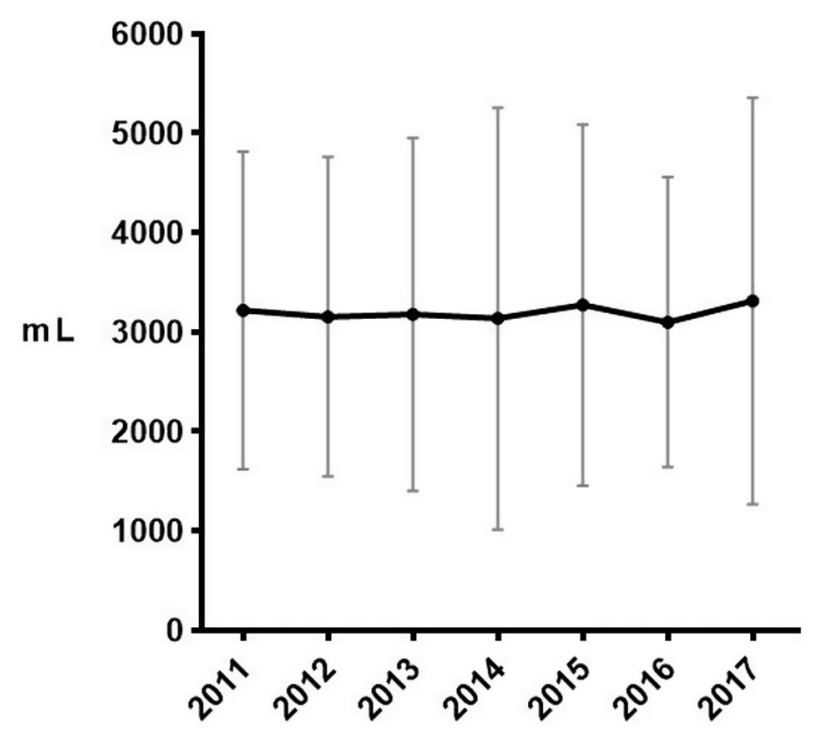

Fig 2. Evolution of administered IV fluids over time (2011-2017). Administered POD 0 IV fluids per year since implementation of enhanced recovery pathway as standard of care (2010). Displayed are means (black dots) and SD (gray bars). SD, standard deviation.

Factors associated with POD 0 IV fluids and POD 2 weight gain above threshold

Table II displays univariate and multivariable factors associated with POD 0 fluid administration $\geq 3$ L and POD 2 weight gain $\geq 2.5$ $\mathrm{kg}$. Independent risk factors to exceed both thresholds were high comorbidity index (ASA score $\geq 3$ ), open surgery, and longer surgical duration $(\geq 180$ minutes, all $P<.001)$. Advanced age $(\geq 70$ years) was associated with POD 0 IV fluid administration below threshold (OR 0.85, $P=.04$ ) but higher odds to exceed weight threshold at POD 2 (OR 1.46, $P=.002$ ).

Duration of the procedure positively correlated with both POD 0 fluids $(\mathrm{r}=0.533, P<.001)$ and POD 2 weight $(\mathrm{r}=0.134, P<.001)$, but with a stronger correlation with fluids than weight (Fig 4, A). Similar observations were made when correlating both fluidrelated parameters with length of stay $(r=0.202, P<.001$ and $\mathrm{r}=0.076, P<.001$, Fig $4, B)$.

\section{Independent risk factors for postoperative complications}

Multivariable analysis revealed open surgery (OR 1.44, $P<.001$ ), ASA $\geq 3$ (OR 1.34, $P=.012$ ), contamination class $\geq 3$ (OR 1.60, $P=.035$ ), malignancy (OR 1.72, $P<.001$ ), administration of $>3 \mathrm{~L}$ POD 0 IV fluids (OR 1.76, $P<.001$ ), and POD 2 weight gain $>2.5 \mathrm{~kg}$ (OR 1.62, $P<.001$ ) as independent risk factors for postoperative complications (Fig 5).

\section{Discussion}

The results of this study suggest that despite the adoption of a restrictive fluid management standard according to ERAS principles, compliance to thresholds remains challenging even in pioneer centers well aware of clinical consequences of fluid overload. Achieving balanced fluids appears to be particularly challenging in patients with high comorbidity indices and during long-lasting open procedures. An adoption of a 0-balance practice did not occur over time, despite standard ERAS implementation and growing experience.

Table I

Patient and surgical characteristics

\begin{tabular}{|c|c|c|c|c|}
\hline & All patients $(\mathrm{N}=5,155)$ & Any complication $(\mathrm{n}=1,450)$ & No complication $(\mathrm{n}=3,705)$ & $P$ \\
\hline Age $(y$, mean $\pm S D)$ & $57.1 \pm 18.2$ & $58.4 \pm 18.9$ & $56.5 \pm 17.7$ & .001 \\
\hline$\geq 70$ y (\%) & $1,413(27.4)$ & $462(31.9)$ & $951(25.7)$ & $<.001$ \\
\hline Sex (male) (\%) & $2,642(51.3)$ & $756(52.1)$ & $1,889(51.0)$ & .457 \\
\hline BMI $\left(\mathrm{kg} / \mathrm{m}^{2}\right.$, mean $\left.\pm \mathrm{SD}\right)$ & $27.1 \pm 6.3$ & $26.4 \pm 6.2$ & $27.3 \pm 6.3$ & $<.001$ \\
\hline$\geq 30 \mathrm{~kg} / \mathrm{m}^{2}(\%)$ & $1,340(26.0)$ & $675(23.9)$ & $994(26.8)$ & .009 \\
\hline ASA Group $(\geq 3, \%)$ & $1,463(28.4)$ & $571(39.4)$ & $892(24.1)$ & $<.001$ \\
\hline Diabetes mellitus (\%) & $560(10.9)$ & $301(13.0)$ & $259(9.2)$ & $<.001$ \\
\hline Preoperative albumin (g/dL) (\%) & $4 \pm 0.6$ & $3.8 \pm 0.7$ & $4.1 \pm 0.5$ & $<.001$ \\
\hline$<3.5 \mathrm{~g} / \mathrm{dL}$ & $338 / 1,686(20.0)$ & $154 / 472(32.6)$ & $184 / 1,214(15.2)$ & $<.001$ \\
\hline \multicolumn{5}{|l|}{ Procedure } \\
\hline Extended (\%) & $2,350(45.6)$ & $768(53.0)$ & $1,582(42.7)$ & $<.001$ \\
\hline Segmental (\%) & $2,805(54.4)$ & $682(47.0)$ & $2,123(57.3)$ & $<.001$ \\
\hline Malignancy (\%) & $3,072(59.6)$ & $986(68.0)$ & $2,086(56.3)$ & $<.001$ \\
\hline Minimally invasive approach (\%) & $3,034(58.9)$ & $712(49.1)$ & $2,322(62.7)$ & $<.001$ \\
\hline Operation duration $(\mathrm{min}$, mean $\pm \mathrm{SD})$ & $201 \pm 97$ & $238 \pm 123$ & $187 \pm 81$ & $<.001$ \\
\hline$\geq 180 \min (\%)$ & $2,617(50.8)$ & $912(62.9)$ & $105(46.0)$ & $<.001$ \\
\hline Contamination class $\geq 3(\%)$ & $281(5.5)$ & $130(9.0)$ & $151(4.1)$ & $<.001$ \\
\hline POD 0 IV fluids (mL, mean \pm SD) & $3,180 \pm 1,800$ & $3,880 \pm 2,540$ & $2,910 \pm 1,310$ & $<.001$ \\
\hline$\geq 3,000 \mathrm{~mL}(\%)$ & $2,320(45.0)$ & $854(58.9)$ & $1,466(39.6)$ & $<.001$ \\
\hline POD 2 weight gain $(\mathrm{kg}$, mean $\pm \mathrm{SD})$ & $2.8 \pm 6.1$ & $3.7 \pm 5.5$ & $2.3 \pm 6.4$ & $<.001$ \\
\hline$\geq 2.5 \mathrm{~kg}$ & $1,024 / 2,052(49.9)$ & $439 / 750(58.5)$ & $585 / 1,302(44.9)$ & \\
\hline \multicolumn{5}{|l|}{ IV fluids $(\mathrm{mL}$, mean $\pm \mathrm{SD})$} \\
\hline POD 1 & $390 \pm 390$ & $390 \pm 460$ & $390 \pm 360$ & .755 \\
\hline POD 2 & $140 \pm 410$ & $230 \pm 500$ & $110 \pm 370$ & $<.001$ \\
\hline \multicolumn{5}{|l|}{ Oral fluids $(\mathrm{mL}$, mean $\pm \mathrm{SD}$ ) } \\
\hline POD 0 & $510 \pm 430$ & $470 \pm 440$ & $530 \pm 420$ & .001 \\
\hline POD 1 & $1,400 \pm 670$ & $1,240 \pm 690$ & $1,450 \pm 650$ & $<.001$ \\
\hline POD 2 & $1,230 \pm 670$ & $1,170 \pm 690$ & $1,260 \pm 660$ & $<.001$ \\
\hline Length of stay (d, median, IQR) & $4(2-9)$ & $7(5-9)$ & $4(2-6)$ & $<.001$ \\
\hline
\end{tabular}

Baseline demographic and surgical parameters of patients with any complication Clavien I-V $(n=1,450)$ and patients without complication $(n=3,705)$.

Bold characters indicate significant values $(P<.05)$.

$I Q R$, interquartile range; $S D$, standard deviation. 
A
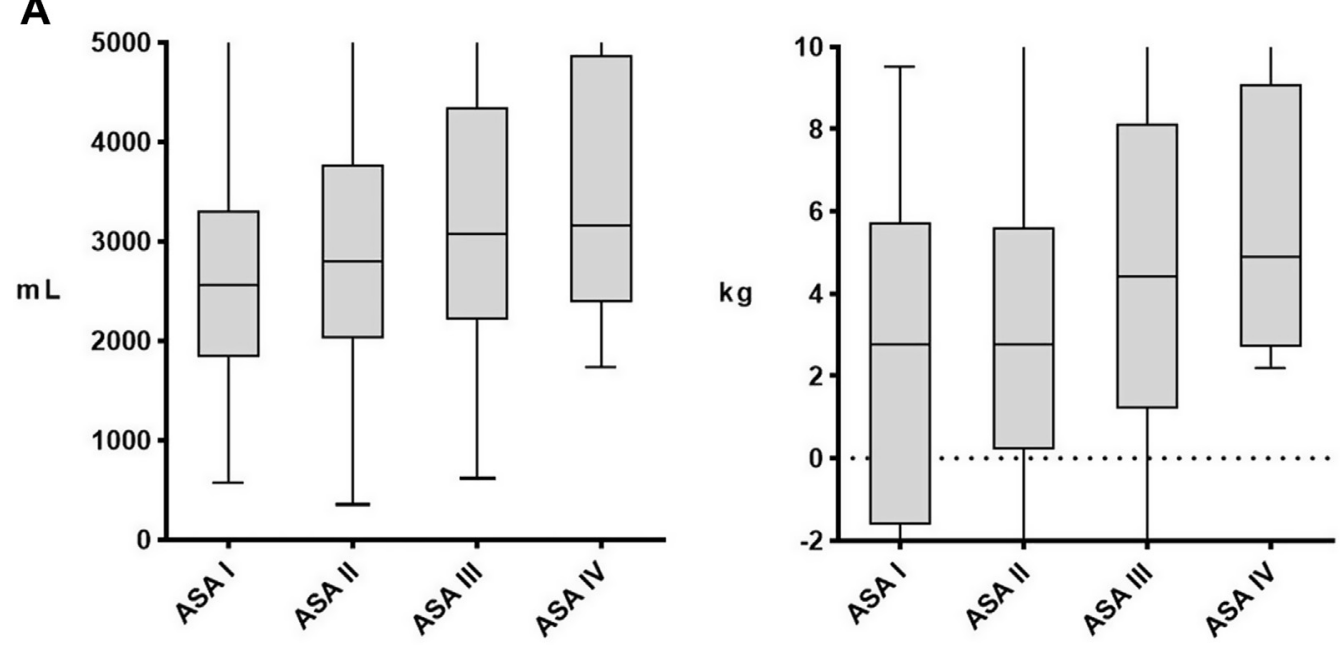

B
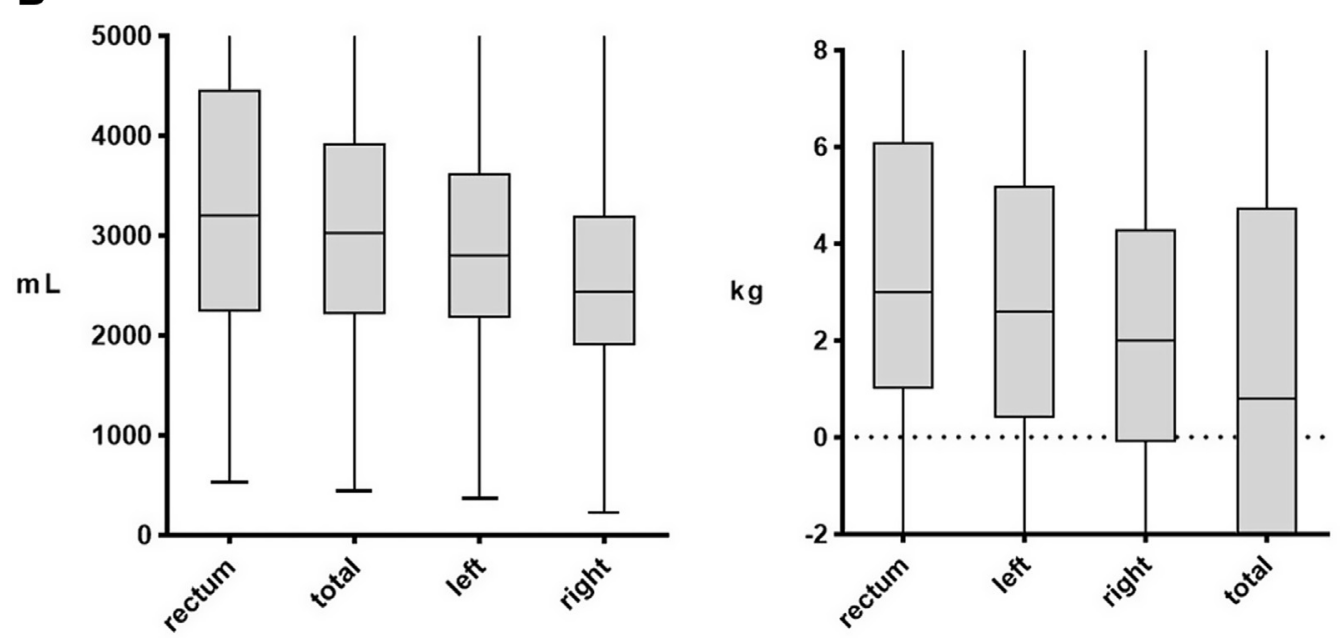

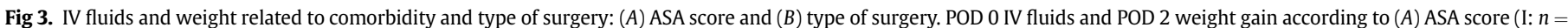

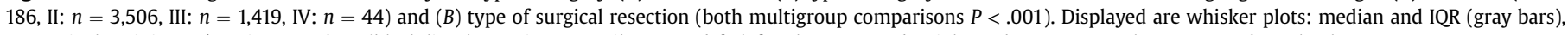
respectively minimum/maximum values (black lines). IQR, interquartile range; left, left colectomy; right, right and transverse colectomy; total, total colectomy.

Table II

Fluids and weight

\begin{tabular}{|c|c|c|c|c|}
\hline & \multicolumn{2}{|l|}{ POD 0 IV fluids $>3 \mathrm{~L}$} & \multicolumn{2}{|c|}{ POD 2 weight gain $>2.5 \mathrm{Kg}$} \\
\hline & Univariate OR (95\% CI) & Multivariable OR $(95 \% \mathrm{CI})$ & Univariate OR (95\% CI) & Multivariable OR (95\% CI) \\
\hline Age $\geq 70 y$ & $0.83(0.73-0.94)$ & $0.85(0.73-0.99)$ & $1.38(1.13-1.68)$ & $1.46(1.15-1.84)$ \\
\hline Sex (male) & $1.17(1.05-1.30)$ & $0.97(0.86-1.09)$ & $0.73(0.61-0.87)$ & $0.69(0.57-0.83)$ \\
\hline $\mathrm{BMI} \geq 30 \mathrm{~kg} / \mathrm{m}^{2}$ & $1.33(1.18-1.51)$ & $1.08(0.94-1.25)$ & $1.51(1.23-1.85)$ & $1.29(1.04-1.59)$ \\
\hline ASA Group $\geq 3$ & $1.57(1.39-1.77)$ & $1.42(1.23-1.64)$ & $1.75(1.44-2.14)$ & $1.50(1.20-1.87)$ \\
\hline Diabetes mellitus & $1.48(1.24-1.76)$ & $1.46(1.19-1.79)$ & $1.43(1.07-1.91)$ & $1.16(0.84-1.60)$ \\
\hline Preoperative albumin $<3.5 \mathrm{~g} / \mathrm{dL}$ & $1.64(1.29-2.09)$ & $-{ }^{*}+$ & $0.61(0.41-0.89)$ & $-*$ \\
\hline Extended surgery & $2.01(1.80-2.25)$ & $1.27(1.11-1.45)$ & - & - \\
\hline Malignancy & - & - & $0.66(0.54-0.80)$ & $0.60(0.48-0.74)$ \\
\hline Open approach & $1.79(1.60-2.00)$ & $1.65(1.45-1.86)$ & $1.73(1.45-2.07)$ & $1.52(1.25-1.84)$ \\
\hline Operation duration $\geq 180 \mathrm{~min}$ & $4.49(3.99-5.06)$ & $4.17(3.66-4.75)$ & $1.59(1.33-1.90)$ & $1.63(1.34-1.98)$ \\
\hline Contamination class $\geq 3$ & $2.45(1.90-3.15)$ & $1.99(1.50-2.63)$ & - & - \\
\hline POD 0 IV fluids $\geq 3,000 \mathrm{~mL}$ & - & - & $1.62(1.36-1.93)$ & $1.34(1.11-1.63)$ \\
\hline
\end{tabular}

Univariate and multivariable analysis of demographic and surgery-related items associated with POD 0 fluid administration of $\geq 3$ L and POD 2 weight gain of $\geq 2.5 \mathrm{~kg}$.

Displayed are OR with $95 \% \mathrm{CI}$.

Bold characters indicate significant values $(P<.05)$.

$C I$, confidence interval; $O R$, odds ratio.

${ }^{*}$ Not retained owing to abundance of missing values. 

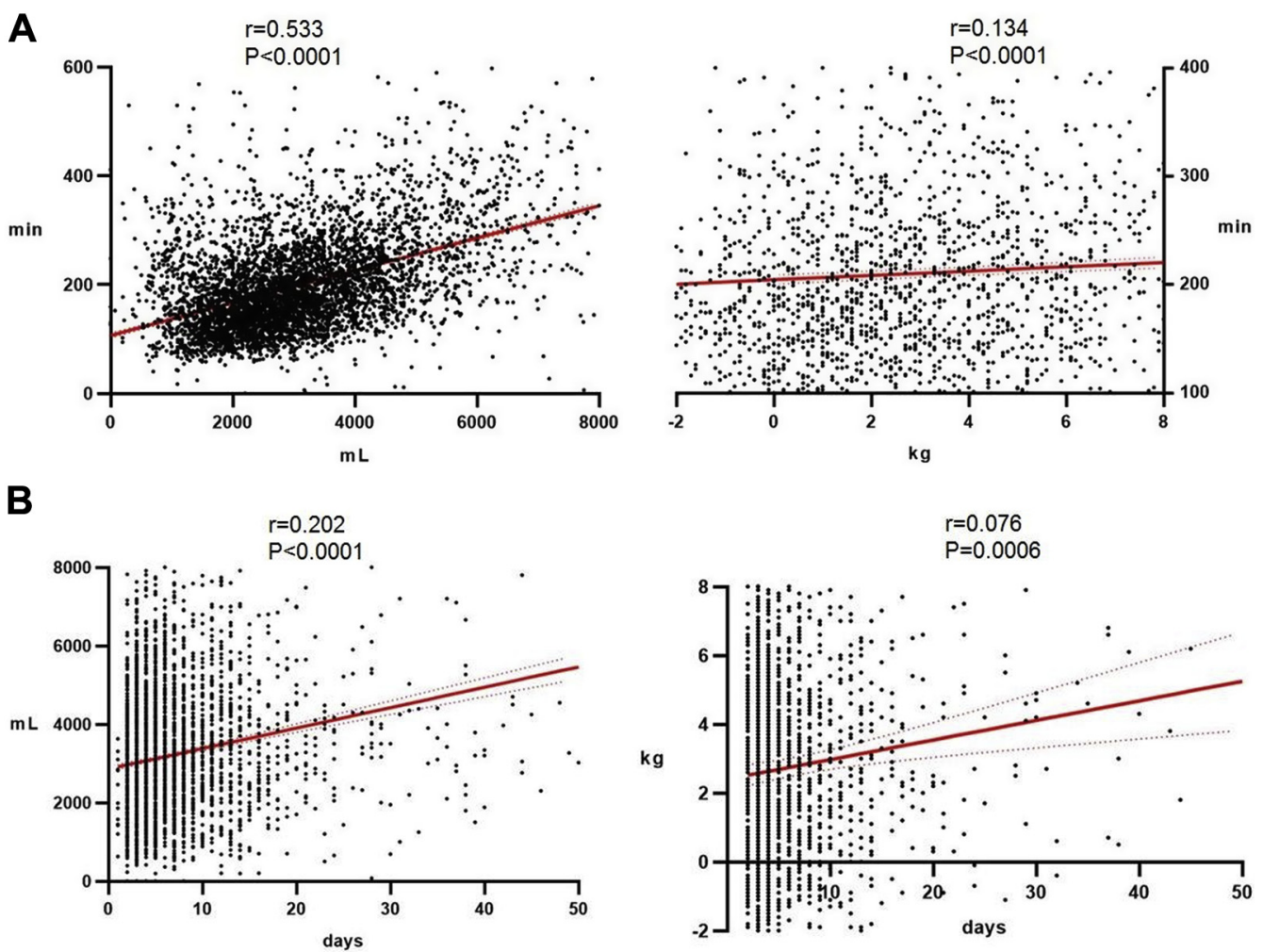

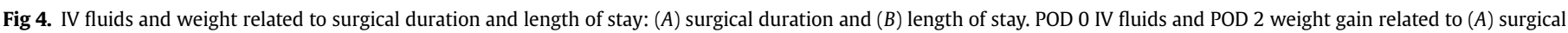
duration and $(B)$ length of hospital stay.

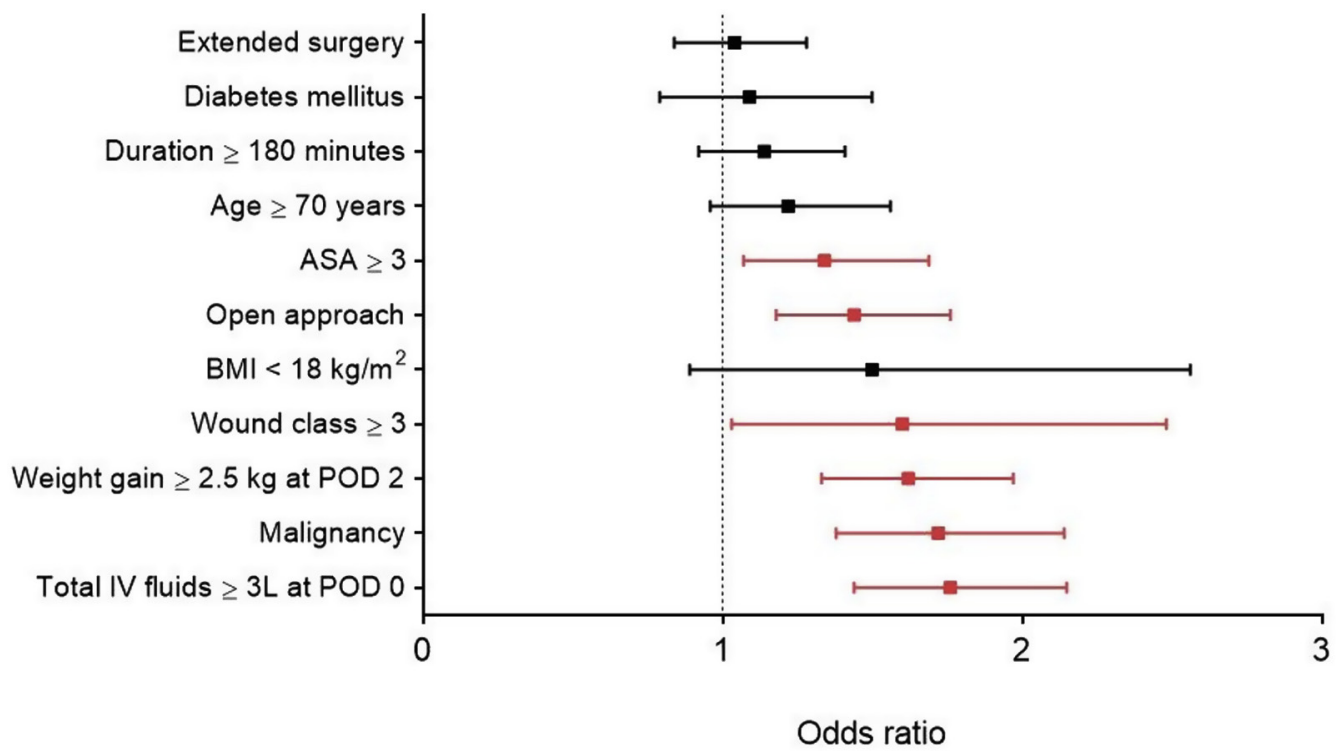

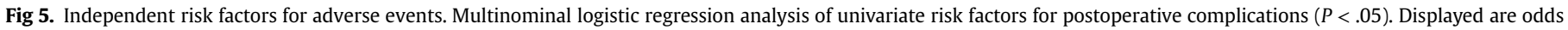
ratios and $95 \%$ confidence intervals. Independent risk factors are highlighted in red. (Color version of figure is available online.)

With a mean POD 0 IV fluid total of slightly over $3 \mathrm{~L}$, perioperative fluid management compares well to former reports in similar ERAS programs. ${ }^{9,20,23}$ More detailed analysis of administered fluids further revealed use of isotonic crystalloids as the standard compound for fluid resuscitation (Fig 1). Reasons for choosing crystalloids over colloids may be related to significantly higher costs and increased hospital stay associated with synthetic colloid solutions. ${ }^{24}$ However, most comparative studies derive from critically ill patients and are thus hardly comparable to the setting of this present study. ${ }^{25}$ Fluid management in the present cohort was in compliance with recent guidelines, recommending routine use of crystalloids in colorectal surgery, with human-derived colloids such as albumin as a safe but costly additional ressource. ${ }^{6}$

The present study emphasizes the importance of best possible adherence to 0 fluid balance because both surrogates for fluid overload ( $\geq 3$ L POD 0 fluids and $\geq 2.5 \mathrm{~kg}$ POD 2 weight gain) were 
independent risk factors for postoperative complications considering a comprehensive array of demographic and surgical confounders. Previous reports from independent centers describe similar associations, with a particularly strong impact of fluid overload on length of stay. ${ }^{20,26}$ Intraoperative fluid management appears to be of critical relevance and is most likely reflected by POD 2 weight because it is challenging to counterbalance fluid overload within 48 hours of surgery. This was confirmed by a recent randomized study from the Mayo Clinic revealing no significant reduction of length of stay despite systematic furosemide administration after surgery. ${ }^{27}$ It is therefore critical to identify patients in whom compliance with set thresholds remains hard to achieve even in ERAS "expert" centers.

Analysis of fluid administration over time revealed no relevant change since implementation of ERAS pathways (Fig 2). Although an average standard of $3 \mathrm{~L}$ was achieved immediately after implementation, approaching the aim of " 0 fluid balance" in an "allcomer" service of tertiary referral institutions remained challenging even with growing experience. Justified concerns may have impeded further fluid restriction over time and further understanding of what triggers IV fluid resuscitation from the anesthesiology perspective is necessary. This specific aspect will be interesting to compare with the experience of other institutions, but studies for comparison are lacking. On the other hand, this consistency over time alleviates potential bias related to the long study period when looking more specifically into further fluidmanagement related details (Fig 3). Patients with higher ASA scores received significantly more IV fluids, and these differences persisted when analyzing POD 2 weight gain. It appears that even in expert centers, fluid overload in polymorbid patients cannot be compensated by POD 2. Although systematic administration of diuretics to all patients is unnecessary or even potentially harm$\mathrm{ful}^{27,28}$ early counter-regulatory measures in selected patients exceeding described thresholds may help to improve recovery, providing tolerance by this fragile subset of patients. To a similar extent, more aggressive therapy in patients undergoing rectal surgery may be warranted because POD 2 weight gain in these patients remains important (Fig 3, B). On the other hand, patients undergoing total colectomy compensated their fluid excess by POD 2 . This may arguably be related to the weight of the resected specimen, paired with prompt functional recovery in young patients with inflammatory bowel disease. In patients $\geq 70$ years, IV fluids were below threshold at POD 0 , whereas weight gain was above threshold at POD 2. This finding may reflect unnecessary IV fluid administration during subsequent postoperative days in older patients on surgical wards and warrants great caution.

Unsurprisingly, surgical duration as a surrogate marker for surgical difficulty correlated well with perioperative fluid volumes $(r=0.533)$. The correlation with POD 2 weight however was very weak and clinically insignificant $(r=0.134)$ and may reflect successful out-balancing of perioperative fluid administration by day 2 in a majority of patients. This holds also true when correlating length of stay to POD 0 fluid volumes (moderate correlation, $r=0.202$ ) and to POD 2 weight, respectively (very weak correlation, $r=0.076)$. The results of this present study may support early initiation of counter-regulatory measures to eliminate (interstitial) fluid excess, including promotion of postoperative ambulation, fluid restriction, and selective diuretic therapy in patients with excessive weight gain and uneventful postoperative recovery. $3,29,30$

This study has limitations related to the bi-institutional design (pooling of data) and the long study period (staff changes, surgical innovation). However, similar implementation history, experience, and organization in both institutions facilitated this joint quality improvement project. Postoperative complications were not regrouped (surgical-medical) or specifically analyzed for the purpose of this study. Of particular importance, acute kidney injury rate was previously analyzed by both ERAS centers and displayed no increased risk. . $^{17,31}$ Some aspects guiding perioperative fluid resuscitation are not discussed in this paper, and an individual, patient-centered approach without dogmatism remains important. The suggested thresholds intend to provide some guidance for elective colorectal resections but are not universally applicable given the individual, multimodal, and complex physiologic response to surgery.

In conclusion, compliance to appropriate fluid thresholds for elective colorectal resections appears to be feasible and sustainable in ERAS centers but remains challenging to achieve in sicker patients and complex procedures. Because fluid overload was associated with postoperative adverse events, postoperative counteractions should be considered in selected patients exceeding intra and postoperative thresholds.

\section{Funding/Support}

The authors have no sources of funding or support to report.

\section{Conflict of interest/Disclosure}

The authors have no related conflicts of interest to declare.

\section{References}

1. Prowle JR, Echeverri JE, Ligabo EV, Ronco C, Bellomo R. Fluid balance and acute kidney injury. Nat Rev Nephrol. 2010;6:107-115.

2. Strunden MS, Heckel K, Goetz AE, Reuter DA. Perioperative fluid and volume management: physiological basis, tools and strategies. Ann Intensive Care 2011;1:2.

3. Voldby AW, Brandstrup B. Fluid therapy in the perioperative setting-a clinical review. I Intensive Care. 2016;4:27.

4. Lobo DN, Bostock KA, Neal KR, Perkins AC, Rowlands BJ, Allison SP. Effect of salt and water balance on recovery of gastrointestinal function after elective colonic resection: a randomised controlled trial. Lancet. 2002;359:1812-1818.

5. Myles PS, Bellomo R, Corcoran T, et al, the Australian and New Zealand College of Anaesthetists Clincial Trials Network, and the Australian and New Zealand Intensive Care Society Clinical Trials Group. Restrictive versus liberal fluid therapy for major abdominal surgery. N Engl J Med. 2018;378:2263-2274.

6. Thiele RH, Raghunathan K, Brudney CS, et al, and the Peripoerative Quality Initiative (POQI) I Workgroup. American Society for Enhanced Recovery (ASER) and Perioperative Quality Initiative (POQI) joint consensus statement on perioperative fluid management within an enhanced recovery pathway for colorectal surgery. Perioper Med (Lond). 2016;5:24.

7. Gustafsson UO, Scott MJ, Hubner M, et al. Guidelines for perioperative care in elective colorectal surgery: Enhanced Recovery After Surgery (ERAS) society recommendations: 2018. World J Surg. 2019;43:659-695.

8. Doherty M, Buggy DJ. Intraoperative fluids: how much is too much? $\mathrm{Br} J$ Anaesth. 2012;109(1):69-79.

9. ERAS Compliance Group. The impact of enhanced recovery protocol compliance on elective colorectal cancer resection: Results from an international registry. Ann Surg. 2015;261:1153-1159.

10. Hübner M, Pache B, Solà J, et al. Thresholds for optimal fluid administration and weight gain after laparoscopic colorectal surgery. BJS Open. 2019;3:532-538.

11. Pache B, Hubner M, Sola J, Hahnloser D, Demartines N, Grass F. Receiver operating characteristic analysis to determine optimal fluid management during open colorectal surgery. Colorectal Dis. 2019;21:234-240.

12. Gustafsson UO, Scott MJ, Schwenk W, et al, the Enhanced Recovery After Surgery (ERAS) Society, for Perioperative Care, European Society for Clinical Nutrition and Metabolism (ESPEN), and the International Association for Surgical Metabolism and Nutrition (IASMEN). Guidelines for perioperative care in elective colonic surgery: Enhanced Recovery After Surgery (ERAS) Society recommendations. World J Surg. 2013:37:259-284.

13. Carmichael JC, Keller DS, Baldini G, et al. Clinical practice guidelines for enhanced recovery after colon and rectal surgery from the American Society of Colon and Rectal Surgeons and Society of American Gastrointestinal and Endoscopic Surgeons. Dis Colon Rectum. 2017;60:761-784.

14. Lovely JK, Maxson PM, Jacob AK, et al. Case-matched series of enhanced versus standard recovery pathway in minimally invasive colorectal surgery. Br J Surg. 2012;99:120-126.

15. Larson DW, Lovely JK, Welsh J, et al, and the Mayo Clinic Care Network Colon Rectal Surgery Enhanced Recovery Collaborative Group. A collaborative for implementation of an evidence-based clinical pathway for enhanced recovery 
in colon and rectal surgery in an affiliated network of healthcare organizations. Jt Comm J Qual Patient Saf. 2018;44:204-211.

16. Grass F, Pache B, Martin D, et al. Feasibility of early postoperative mobilisation after colorectal surgery: A retrospective cohort study. Int J Surg. 2018;56: $161-166$.

17. Grass F, Slieker J, Frauche P, et al. Postoperative urinary retention in colorectal surgery within an enhanced recovery pathway. J Surg Res. 2017;207:70-76.

18. Gupta R, Gan TJ. Peri-operative fluid management to enhance recovery. Anaesthesia. 2016:71(Suppl 1):40-45.

19. Hubner M, Lovely JK, Huebner M, Slettedahl SW, Jacob AK, Larson DW. Intrathecal analgesia and restrictive perioperative fluid management within enhanced recovery pathway: hemodynamic implications. J Am Coll Surg. 2013;216:1124-1134.

20. Asklid D, Segelman J, Gedda C, Hjern F, Pekkari K, Gustafsson UO. The impact of perioperative fluid therapy on short-term outcomes and 5-year survival among patients undergoing colorectal cancer surgery - A prospective cohort study within an ERAS protocol. Eur I Surg Oncol. 2017;43: 1433-1439.

21. Grass F, Lovely JK, Crippa J, Hubner M, Mathis KL, Larson DW. Potential association between perioperative fluid management and occurrence of postoperative ileus. Dis Colon Rectum. 2020;63:68-74.

22. Clavien PA, Barkun J, de Oliveira ML, et al. The Clavien-Dindo classification of surgical complications: five-year experience. Ann Surg. 2009;250: 187-196.
23. Quinn TD, Brovman EY, Urman RD. Analysis of variability in intraoperative fluid administration for colorectal surgery: An argument for goal-directed fluid therapy. J Laparoendosc Adv Surg Tech A. 2017;27:892-897.

24. Morris C, Rogerson D. What is the optimal type of fluid to be used for perioperative fluid optimisation directed by oesophageal Doppler monitoring? Anaesthesia. 2011;66:819-827.

25. Qureshi SH, Rizvi SI, Patel NN, Murphy GJ. Meta-analysis of colloids versus crystalloids in critically ill, trauma and surgical patients. Br J Surg. 2016;103: $14-26$.

26. Regenbogen SE, Shah NJ, Collins SD, Hendren S, Englesbe MJ, Campbell Jr DA. Population-based assessment of intraoperative fluid administration practices across three surgical specialties. Ann Surg. 2017;265:930-940.

27. Danelich IM, Bergquist JR, Bergquist WJ, et al. Early diuresis after colon and rectal surgery does not reduce length of hospital stay: results of a randomized trial. Dis Colon Rectum. 2018;61:1187-1195.

28. Varbanova M, Akca O. Diuretics and the perioperative fluid balance. Dis Colon Rectum. 2018;61:1125-1127.

29. Bajwa SS, Kulshrestha A. Diagnosis, prevention and management of postoperative pulmonary edema. Ann Med Health Sci Res. 2012;2:180-185.

30. Pedziwiatr M, Mavrikis J, Witowski J, et al. Current status of enhanced recovery after surgery (ERAS) protocol in gastrointestinal surgery. Med Oncol. 2018;35:95.

31. Grass F, Lovely JK, Crippa J, Mathis KL, Hubner M, Larson DW. Early acute kidney injury within an established enhanced recovery pathway: Uncommon and transitory. World J Surg. 2019;43:1207-1215. 